\begin{tabular}{|l|l|l|l|l|l|}
\hline J. Tek. Ling & Vol. 12 & No. 2 & Hal. $171-186$ & Jakarta, Mei 2011 & ISSN 1441-318X \\
\hline
\end{tabular}

\title{
ISOLASI, IDENTIFIKASI, DAN SKRINING JAMUR ENDOFIT PENGHASIL AGEN BIOKONTROL DARI TANAMAN DI LAHAN PERTANIAN DAN HUTAN PENUNJANG GUNUNG SALAK
}

\author{
Suciatmih, Yuliar, dan D. Supriyati \\ Bidang Mikrobiologi, Puslit Biologi - LIPI \\ CSC Jl. Raya Jakarta-Bogor Km 46, Cibinong \\ e-mail: suciatmih2008@yahoo.ca
}

\begin{abstract}
Abstrak
Isolation of endophytic fungi was done to find alternative microorganisms as biocontrol agents against Rhizoctonia solani Kuhn, a soil borne pathogen on many agricultural crops. The research objectives were 1) to isolate and identify endophytic fungi colonize plants growing on agricultural and Mount Salak supporting forest lands in the Villages of Parakan Salak and Cimalati, Sukabumi; and 2) to screen for their biocontrol agent activity againt $R$. solani. Diameter of $R$. solani was measured on day 2 after inoculation, and its percent inhibition of growth by endophytic fungi is calculated using the formula Skidmore \& Dickinson (1976). The results indicated that 214 isolates of endophytic fungi were isolated from 96 plant species that growing in both places. Endophytic fungi isolated including in the group of Aspergillus, Cladosporium, Colletotrichum, Curvularia, Drechslera, Fusarium, Guignardia, Mucor, Nigrospora, Paecilomyces, Penicillium, Pestalotiopsis, Phoma, Phomopsis, Rhizoctonia, and endophytic fungi that have not been identified. Of the 214 fungal isolates tested, 39 isolates (18.22\%) could inhibit the growth of R. solani from $10.18 \%$ to $58.99 \%$ with a percent inhibition. The highest growth inhibition of $R$. solani were shown respectively by an unidentified fungus isolated from Hyptis capitata Jack (58.99\%), Cladosporium sp. isolated from jeruk bali (Citrus grandis (L.) Osbeck) (55.42\%), Pestalotiopsis sp. isolated from pine apple (Ananas comosus (L.) Merr.) (53.85\%), and Paecilomyces lilacinus (Thom) Samson isolated from banyan (Ficus benyamina L.) (51.81\%).
\end{abstract}

Key words: biocontrol agent; endophytic fungi; percentage inhibition of growth

\section{PENDAHULUAN}

\subsection{Latar belakang}

Rhizoctonia solani Kuhn adalah patogen tular tanah yang sangat umum, berdistribusi luas, dan mempunyai banyak tanaman inang, seperti alfalfa, jagung, kacang tanah, kentang, ketimun, pepaya, terong, tomat dan lain-lain. 1) Jamur tersebut selain dapat menyerang bagian tanaman yang ada di dalam tanah, seperti biji, hifokotil, dan akar, juga dapat menginfeksi bagian tanaman di atas tanah, seperti polong, buah, daun, dan batang sehingga dapat menurunkan produksi tanaman-tanaman tersebut ${ }^{2}$.

Sampai saat ini, penanggulangan jamur patogen tersebut menggunakan 
fungisida baik yang diaplikasikan pada biji maupun tanah. Tetapi, fungisida tidak efektif melawan patogen tersebut karena propagul patogen yang berdistribusi didalam tanah seringkali di luar jangkauan bahan kimia ${ }^{3)}$. Selain itu, penggunaan fungisida dapat menyebabkan terbunuhnya mikroorganisme bukan sasaran, timbulnya strain organisme pengganggu tumbuhan (OPT) yang resisten terhadap fungisida, dan membahayakan kesehatan serta lingkungan ${ }^{4}$.

Berdasarkan keadaan tersebut, diperlukan usaha pencarian sumber genetik baru untuk dikembangkan menjadi mikroorganisme alternatif sebagai agen biokontrol melalui isolasi dan identifikasi jamur endofit lokal yang mengkolonisasi berbagai tanaman yang tumbuh di lahan pertanian dan lahan hutan penunjang Gunung Salak yang ada di Desa Parakan Salak dan Cimalati, Sukabumi; serta mensekrin aktivitas agen biokontrolnya terhadap $R$. solani. Bacon et al. ${ }^{5)}$ melaporkan bahwa jamur endofit adalah jamur yang sekurangkurangnya selama periode tertentu dari siklus hidupnya mengkolonisasi jaringan tumbuhan tanpa menimbulkan gejala penyakit atau kerusakan apa pun pada tumbuhan. Peneliti yang sama menginformasikan bahwa jamur endofit dapat menghasilkan dan mensekresikan bahan bioaktif termasuk mikotoksin, antibiotik, enzim, dan metabolit sekunder lainnya, termasuk zat antikanker.

\subsection{Tujuan}

Penelitian ini bertujuan untuk mendapatkan jamur endofit sebagai agen biokontrol terhadap $R$. solani.

\section{METODOLOGI}

Isolat jamur endofit diperoleh dengan cara mengisolasinya dari organ tanaman sehat kemudian memurnikan dan mengidentifikasinya. Isolat jamur endofit yang sudah murni selanjutnya diskrining aktivitas agen biokontrolnya terhadap $R$. solani.

\subsection{Isolasi jamur endofit}

Organ tanaman sehat seperti akar, umbi, batang, dan daun yang akan digunakan untuk mengisolasi jamur, dicuci dengan air kran hingga bersih. Bagian ujung, pangkal, dan tengah dari akar, umbi, batang, dan daun, dipotong $1 \mathrm{~cm} \times 1 \mathrm{~cm}$. Potongan dari masing-masing organ tanaman kemudian ditempatkan dalam masing-masing botol jam $^{6}$.

Potongan bagian tanaman disterilisasi dengan alkohol $70 \%$ selama 1 menit dan pemutih (mengandung 5,3\% natrium hipoklorit) selama 2 menit. Potongan bagian tanaman kemudian dibilas dengan air steril sebanyak 3 kali dan dimasukkan ke dalam tissue tebal steril selama 3-4 jam (sampai kering). Isolasi jamur dilakukan dengan teknik direct planting, yaitu dengan meletakkan potongan bagian tanaman yang sudah kering (6 potongan) di atas permukaan $2 \%$ medium yang telah ditambahkan kloramfenikol (200 $\mathrm{mg} / 1$ liter medium). Seluruh medium yang telah diinokulasi, diinkubasi pada suhu ruang $\left(27-28^{\circ} \mathrm{C}\right)$. Morfologi koloni yang penampakan, warna, dan ukurannya sama dianggap isolat yang sama. Setiap koloni representatif dipisahkan menjadi isolat-isolat tersendiri.

\subsection{Pemurnian jamur endofit}

Pemurnian jamur pembentuk spora dilakukan dengan cara isolasi spora tunggal 7). Masing-masing biakan jamur endofit, ditanam pada medium PDA miring dan diinkubasi selama 5 hari. Biakan jamur yang telah berumur 5 hari ditambahkan 4 $\mathrm{ml}$ akuades steril. Spora dikerik dengan jarum tanam hingga terlepas dari agar dan divorteks untuk memperoleh suspensi spora. Suspensi spora diencerkan dengan akuades steril sampai mencapai pengenceran 103. Sebanyak 0,1 ml suspensi disebarkan secara merata pada permukaan cawan petri berisi medium PDA dan diinkubasi pada suhu ruang $\left(27-28^{\circ} \mathrm{C}\right)$. Koloni tunggal 
yang tumbuh kemudian dipindahkan dalam PDA miring untuk working culture dan stock culture.

Pemurnian jamur tidak membentuk spora dilakukan dengan cara menumbuhkan jamur pada medium PDA. Dengan bantuan mikroskop stereo, hifa tunggal dari jamur kemudian ditransfer ke medium PDA miring untuk working culture dan stock culture.

\subsection{Identifikasi jamur endofit}

Isolat tunggal dari jamur kemudian diidentifikasi secara morfologi meliputi pengamatan makroskopis dan mikroskopis dengan menggunakan buku identifikasi dari $8,9,6)$.

\subsection{Skrining aktivitas agen biokontrol terhadap $R$. solani oleh jamur endofit}

\subsubsection{Pembuatan inokulum jamur endofit}

Sebanyak $5 \mathrm{ml}$ akuades steril dimasukkan ke dalam tabung reaksi yang masing-masing berisi jamur endofit pembentuk spora yang telah berumur 7 hari. Kultur kemudian dikerik perlahan dengan menggunakan jarum tanam untuk memperoleh suspensi spora. Jamur endofit yang tidak membentuk spora ditumbuhkan dalam medium PDA selama 7 hari kemudian dicetak dengan sedotan pop ice.

\subsubsection{Inokulasi jamur endofit}

Sebanyak $2 \mathrm{ml}(10 \%)$ suspensi konidia atau 2 bulatan miselium jamur endofit ditambahkan ke dalam Erlemeyer $100 \mathrm{ml}$ yang masing-masing berisi $20 \mathrm{ml}$ medium fermentasi potato dextrose yeast (PDY). Medium diinkubasi dalam shaker incubator pada suhu ruang $\left(27-28^{\circ} \mathrm{C}\right)$ dan kecepatan agitasi 90 rpm selama 5 hari $^{10)}$.

\subsubsection{Pemanenan filtrat yang mengandung agen biokontrol}

Agen biokontrol dipanen dengan cara memisahkan biomassa sel dengan sentrifugasi $6000 \mathrm{rpm}$ selama 10 menit $^{111}$. Filtrat digunakan sebagai crude biocontrol agent untuk pengujian toksisitas.

\subsubsection{Pengujian}

Sebanyak $200 \mu$ filtrat hasil fermentasi jamur endofit yang berumur 5 hari dicampur dengan $5 \mathrm{ml}$ medium PDA dalam tabung reaksi dan divorteks kemudian dituang ke dalam cawan petri. Setelah medium mengeras, biakan $R$. solani yang telah diremajakan dengan cara ditumbuhkan pada medium PDA dan telah berumur 5-7 hari, diambil menggunakan sedotan pop ice dan ditumbuhkan di tengah medium tersebut. Untuk kontrol, filtrat hasil fermentasi jamur endofit diganti dengan $200 \mu$ lakuades yang telah disterilisasi. Diameter jamur patogen diukur pada hari ke-2 setelah inokulasi, dan persen hambatan pertumbuhannya dihitung berdasarkan rumus Skidmore \& Dickinson ${ }^{12)}$ :

$$
\mathrm{PI}=\mathrm{C}-\mathrm{T} \times 100
$$

$$
\begin{aligned}
\mathrm{PI}= & \text { persen hambatan pertumbuhan } \\
& \text { miselium }(\%) \\
\mathrm{C}= & \text { diameter miselium patogen pada cawan } \\
& \text { petri kontrol }(\mathrm{cm}) \\
\mathrm{T}= & \begin{array}{l}
\text { diameter miselium patogen pada cawan } \\
\text { petri perlakuan }(\mathrm{cm})
\end{array}
\end{aligned}
$$

\section{HASIL DAN PEMBAHASAN}

\subsection{Hasil}

Kecuali tanaman kangkung dan genjer, 48 spesies tanaman (41 spesies tanaman yang tumbuh di lahan pertanian dan 7 spesies tanaman yang tumbuh di lahan hutan penunjang G. Salak) di Desa Parakan Salak, Sukabumi, semuanya diketahui 
menjadi inang jamur (Tabel 1). Dari 101 isolat jamur yang terisolasi, 24 isolat berhasil diidentifikasi sampai spesies, 57 isolat sampai marga (genus), dan 20 isolat belum teridentifikasi. Isolat-isolat tersebut termasuk dalam kelompok Colletotrichum, Curvularia,
Drechslera, Fusarium, Guignardia, Mucor, Nigrospora, Pestalotiopsis, Phomopsis, dan Rhizoctonia.

Seratus tiga belas isolat berhasil diisolasi dari 49 spesies tanaman ( 37 spesies

Tabel 1. Jamur endofit pada tanaman di lahan pertanian dan hutan penunjang di Desa Parakan Salak, Sukabumi.

\begin{tabular}{|c|c|c|c|}
\hline No & Tanaman inang & Bagian tanaman & Jamur \\
\hline \multicolumn{4}{|c|}{ Tanaman Pertanian } \\
\hline 1. & Acacia mangium Willd & $\begin{array}{c}\text { Tangkai daun } \\
\text { Daun }\end{array}$ & $\begin{array}{c}\text { Guignardia } \\
\text { endophyllicola } \\
\text { Okane, Nakagiri, \& Ito } \\
\text { Unidentified }\end{array}$ \\
\hline 2. & Babadotan (Ageratum conyzoides L.) & Tangkai daun \& daun & Fusarium sp. \\
\hline 3. & Beringin (Ficus benyamina L.) & $\begin{array}{c}\text { Tangkai daun } \\
\text { Daun }\end{array}$ & $\begin{array}{l}\text { Colletotrichum sp. } \\
\text { Curvularia sp. } \\
\text { Colletotrichum sp. } \\
\text { Fusarium oxysporum } \\
\text { Schlecht }\end{array}$ \\
\hline 4. & Bintaro (Cerbera manghas L.) & $\begin{array}{c}\text { Tangkai daun } \\
\text { Daun }\end{array}$ & $\begin{array}{l}\text { Colletotrichum sp. } \\
\text { G. endophyllicola } \\
\text { Colletotrichum sp. }\end{array}$ \\
\hline 5. & Cabe rawit (Capsicum frutescens L.) & Tangkai daun & Colletotrichum sp. \\
\hline 6. & Caisin (Brassica chinensis L.) & $\begin{array}{c}\text { Tangkai daun } \\
\text { Daun }\end{array}$ & $\begin{array}{l}\text { Mucor sp. } \\
\text { Colletotrichum sp. } \\
\text { Fusarium sp. }\end{array}$ \\
\hline 7. & Daun bawang (Allium fistulosum L.) & $\begin{array}{l}\text { Akar } \\
\text { Batang }\end{array}$ & $\begin{array}{l}\text { Fusarium sp. } \\
\text { Fusarium sp. } \\
\text { F. oxysporum } \\
\text { Colletotrichum sp. }\end{array}$ \\
\hline 8. & Durian * (Durio zibethinus Murray) & Tangkai daun $\&$ daun & Unidentified \\
\hline 9. & Durian (Durio zibethinus Murray) & Tangkai daun \& daun & Unidentified \\
\hline 10. & Eupatorium odoratum L. & $\begin{array}{c}\text { Tangkai daun } \\
\text { Daun }\end{array}$ & $\begin{array}{c}\text { Fusarium sp. } \\
\text { G. endophyllicola }\end{array}$ \\
\hline 11. & $\begin{array}{l}\text { Genjer (Limnocharis flava (L.) } \\
\text { Buchenou }\end{array}$ & $\begin{array}{l}\text { Batang } \\
\text { Daun }\end{array}$ & - \\
\hline 12. & Jagung (Zea mays L.) & Batang & $\begin{array}{l}\text { Drechslera sp. } \\
\text { Fusarium sp. }\end{array}$ \\
\hline
\end{tabular}




\begin{tabular}{|c|c|c|c|}
\hline No & Tanaman inang & Bagian tanaman & Jamur \\
\hline 13. & $\begin{array}{l}\text { Jahe merah (Zingiber officinale } \\
\text { Roscoe) }\end{array}$ & $\begin{array}{l}\text { Batang } \\
\text { Daun }\end{array}$ & $\begin{array}{c}\text { Fusarium sp. } \\
\text { G. endophyllicola } \\
\text { Fusarium sp. }\end{array}$ \\
\hline 14. & $\begin{array}{l}\text { Jambu air (Syzygium aqueum } \\
\text { (Burm.f.) Alston) }\end{array}$ & $\begin{array}{c}\text { Tangkai daun } \\
\text { Daun }\end{array}$ & $\begin{array}{c}\text { F. oxysporum } \\
\text { G. endophyllicola } \\
\text { Colletotrichum sp }\end{array}$ \\
\hline 15. & Jambu biji (Psidium guajava L.) & $\begin{array}{c}\text { Tangkai daun } \\
\text { Daun }\end{array}$ & $\begin{array}{l}\text { G. endophyllicola } \\
\text { Fusarium sp. } \\
\text { Fusarium sp. } \\
\text { G. endophyllicola }\end{array}$ \\
\hline 16. & $\begin{array}{l}\text { Jambu bol (Syzygium malaccense } \\
\text { Merr. \& Perry) }\end{array}$ & $\begin{array}{c}\text { Tangkai daun } \\
\text { Daun } \\
\end{array}$ & $\begin{array}{c}\text { Pestalotiopsis sp. } \\
\text { Fusarium sp. }\end{array}$ \\
\hline 17. & Jambu mawar * (Eugenia jambos L.) & $\begin{array}{c}\text { Tangkai daun } \\
\text { Daun }\end{array}$ & $\begin{array}{l}\text { Colletotrichum sp } \\
\text { Pestalotiopsis sp. } \\
\text { G. endophyllicola }\end{array}$ \\
\hline 18. & Jarak (Ricinus communis L.) & $\begin{array}{c}\text { Tangkai daun } \\
\text { Buah }\end{array}$ & $\begin{array}{c}\text { Unidentified } \\
\text { Mucor sp. } \\
\text { Pestalotiopsis sp. }\end{array}$ \\
\hline 19. & $\begin{array}{l}\text { Jeruk nipis (Citrus aurantifolia (Christ. } \\
\text { Et panz.) Swingle) }\end{array}$ & $\begin{array}{l}\text { Tangkai daun } \\
\text { Daun } \\
\text { Buah }\end{array}$ & $\begin{array}{c}\text { Unidentified } \\
\text { Colletotrichum sp } \\
\text { G. endophyllicola } \\
\text { F. oxysporum }\end{array}$ \\
\hline 20. & $\begin{array}{l}\text { Kacang panjang (Vigna unguiculata } \\
\text { (L.) Walp. }\end{array}$ & Daun & $\begin{array}{l}\text { Colletotrichum sp } \\
\text { Fusarium } \mathrm{sp} .\end{array}$ \\
\hline 21. & $\begin{array}{l}\text { Kaliandra (Calliandra calothyrsus } \\
\text { Meissner) }\end{array}$ & Tangkai daun \& daun & Unidentified \\
\hline 22. & Kangkung (Ipomoea aquatica Forsk) & $\begin{array}{c}\text { Tangkai daun } \\
\text { Daun } \\
\text { Batang } \\
\end{array}$ & - \\
\hline 23. & Kapri (Pisum sativum L.) & $\begin{array}{l}\text { Daun } \\
\text { Polong }\end{array}$ & $\begin{array}{l}\text { Colletotrichum sp } \\
\text { Colletotrichum sp }\end{array}$ \\
\hline
\end{tabular}




\begin{tabular}{|c|c|c|c|}
\hline No & Tanaman inang & Bagian tanaman & Jamur \\
\hline 24. & Kedelai (Glycine max (L.) Merr. & $\begin{array}{l}\text { Tangkai daun } \\
\text { Daun } \\
\text { Bunga } \\
\text { Polong }\end{array}$ & $\begin{array}{l}\text { Unidentified } \\
\text { G. endophyllicola } \\
\text { Unidentified } \\
\text { Fusarium sp. }\end{array}$ \\
\hline 25. & $\begin{array}{l}\text { Kedongdongan (Lannea } \\
\text { coromandelica (Houtt.) Merr.) }\end{array}$ & Daun & G. endophyllicola \\
\hline 26. & Ketimun (Cucumis sativus L.) & Tangkai daun \& daun & Unidentified \\
\hline 27. & Lada (Piper nigrum L.) & $\begin{array}{l}\text { Tangkai daun } \\
\text { Daun }\end{array}$ & $\begin{array}{c}\text { Unidentified } \\
\text { G. endophyllicola }\end{array}$ \\
\hline 28. & Lantana camara L. & Tangkai daun & Rhizoctonia sp. \\
\hline 29. & $\begin{array}{l}\text { Mahkota dewa (Phaleria capitata } \\
\text { Jack) }\end{array}$ & $\begin{array}{c}\text { Tangkai daun } \\
\text { Daun }\end{array}$ & $\begin{array}{l}\text { Colletotrichum sp. } \\
\text { Fusarium sp. } \\
\text { Phomopsis sp. } \\
\text { Colletotrichum sp. }\end{array}$ \\
\hline 30. & Manggis (Garcinia mangostana L.) & $\begin{array}{l}\text { Tangkai daun } \\
\text { Daun }\end{array}$ & $\begin{array}{l}\text { Unidentified } \\
\text { Mucor sp. }\end{array}$ \\
\hline 31. & Mengkudu (Morindra citrifolia L.) & $\begin{array}{c}\text { Tangkai daun } \\
\text { Daun } \\
\text { Buah }\end{array}$ & $\begin{array}{c}\text { Fusarium sp. } \\
\text { Colletotrichum sp. } \\
\text { Unidentified }\end{array}$ \\
\hline 32. & $\begin{array}{l}\text { Nangka (Artocarpus heterophyllus } \\
\text { Lamk) }\end{array}$ & $\begin{array}{c}\text { Tangkai daun } \\
\text { Daun } \\
\end{array}$ & $\begin{array}{c}\text { Nigrospora oryzae } \\
\text { (Berk. \& Broome) Petch } \\
\text { Colletotrichum sp. }\end{array}$ \\
\hline 33. & Padi (Oryza sativa L) & Daun & Colletotrichum sp. \\
\hline 34. & Pala (Myristica fragrans Houtt) & $\begin{array}{c}\text { Tangkai daun } \\
\text { Daun }\end{array}$ & $\begin{array}{l}\text { Colletotrichum sp. } \\
\text { Colletotrichum sp. } \\
\text { G. endophyllicola }\end{array}$ \\
\hline 35. & Pepaya (Carica papaya L.) & Daun & Unidentified \\
\hline 36. & $\begin{array}{l}\text { Rambutan (Nepheleum lappaceum } \\
\text { L.) }\end{array}$ & $\begin{array}{c}\text { Tangkai daun } \\
\text { Daun } \\
\end{array}$ & $\begin{array}{c}\text { Unidentified } \\
\text { G. endophyllicola }\end{array}$ \\
\hline 37. & Talas (Colocasia sp.) & Umbi & Fusarium sp. \\
\hline 38. & $\begin{array}{l}\text { Teh penduduk (Camellia sinensis (L.) } \\
\text { Kuntze }\end{array}$ & Tangkai daun & Colletotrichum sp. \\
\hline
\end{tabular}




\begin{tabular}{|c|c|c|c|}
\hline No & Tanaman inang & Bagian tanaman & Jamur \\
\hline 39. & Teh (Camellia sinensis (L.) Kuntze & $\begin{array}{c}\text { Tangkai daun } \\
\text { Bunga } \\
\text { Buah }\end{array}$ & $\begin{array}{c}\text { Pestalotiopsis sp. } \\
\text { Pestalotiopsis sp. } \\
\text { Unidentified }\end{array}$ \\
\hline 40. & Ubi jalar (Ipomoea batatas (L.) Lamk & $\begin{array}{c}\text { Batang } \\
\text { Daun }\end{array}$ & $\begin{array}{c}\text { Fusarium sp. } \\
\text { Colletotrichum sp } \\
\text { Fusarium } \mathrm{sp} .\end{array}$ \\
\hline 41. & Ubi kayu (Manihot esculenta Crantz) & Tangkai daun & G. endophyllicola \\
\hline \multicolumn{4}{|c|}{ Tanaman hutan penunjang } \\
\hline 42. & HP-1(Toona sinensis Roem) & Tangkai daun & Unidentified \\
\hline 43. & $\begin{array}{c}\text { HP-3 (Crotalaria usaramoensis } \\
\text { Backer) }\end{array}$ & $\begin{array}{l}\text { Tangkai daun } \\
\text { Daun \& polong }\end{array}$ & $\begin{array}{l}\text { Colletotrichum sp } \\
\text { F. oxysporum } \\
\text { Fusarium sp. } \\
\text { Unidentified }\end{array}$ \\
\hline 44. & $\begin{array}{c}\text { HP-4 (Gravillea robusta A. Cunn. Ex } \\
\text { R. Br.) }\end{array}$ & $\begin{array}{l}\text { Tangkai daun } \\
\text { Daun }\end{array}$ & $\begin{array}{l}\text { Phomopsis sp. } \\
\text { Colletotrichum sp. }\end{array}$ \\
\hline 45. & HP-5 (Tephrosia vogelii J.D. Hooker) & $\begin{array}{c}\text { Tangkai daun \& } \\
\text { polong }\end{array}$ & Unidentified \\
\hline 46. & $\begin{array}{c}\text { HP-7 (Karet (Hevea brasiliensis (Willd. } \\
\text { Ex A. Juss.) Muell. Arg.) }\end{array}$ & $\begin{array}{c}\text { Tangkai daun } \\
\text { Daun }\end{array}$ & $\begin{array}{c}\text { G. endophyllicola } \\
\text { Unidentified }\end{array}$ \\
\hline 47. & $\begin{array}{c}\text { HP-9 (Pyrrosia nummulariifolia (Swatz) } \\
\text { Ching }\end{array}$ & $\begin{array}{c}\text { Batang \& akar } \\
\text { Daun }\end{array}$ & $\begin{array}{c}\text { Unidentified } \\
\text { Colletotrichum sp }\end{array}$ \\
\hline 48. & Guioa diplopetala (Hassk) Radlk. & $\begin{array}{c}\text { Tangkai daun } \\
\text { Daun }\end{array}$ & $\begin{array}{l}\text { G. endophyllicola } \\
\text { G. endophyllicola }\end{array}$ \\
\hline
\end{tabular}

tanaman yang tumbuh di lahan pertanian dan 12 spesies tanaman yang tumbuh di lahan hutan penunjang G. Salak) di Desa Cimalati, Sukabumi (Tabel 2). Dari jumlah tersebut, 20 isolat berhasil diidentifikasi sampai spesies, 69 isolat sampai marga, 1 isolat sampai kelas, 1 isolat sampai famili, dan 22 isolat belum teridentifikasi. Isolat-isolat tersebut termasuk dalam kelompok Aspergillus, Cladosporium, Colletotrichum, Curvularia, Drechslera, Fusarium, Guignardia, Nigrospora, Paecilomyces, Penicillium, Pestalotiopsis, Phoma, dan Phomopsis. 
Tabel 2. Jamur endofit pada tanaman di lahan pertanian dan hutan penunjang di Desa Cimalati, Sukabumi.

\begin{tabular}{|c|c|c|c|}
\hline No & Tanaman inang & Bagian tanaman & Jamur \\
\hline & Tanaman Pertanian & & \\
\hline 1. & Agave sisalana Perr. & $\begin{array}{l}\text { *Tangkai daun } \\
\text { Daun }\end{array}$ & $\begin{array}{l}\text { Guignardia } \\
\text { endophyllicola } \\
\text { Okane, Nakagiri, \& Ito } \\
\text { Unidentified }\end{array}$ \\
\hline 2. & Asparagus officinalis L. & $\begin{array}{l}\text { Tangkai daun } \\
\text { Daun }\end{array}$ & $\begin{array}{l}\text { Colletotrichum sp. } \\
\text { Colletotrichum sp. } \\
\text { Phomopsis sp. }\end{array}$ \\
\hline 3. & $\begin{array}{l}\text { Bayam merah (Altenanthera amoena } \\
\text { Voss.) }\end{array}$ & *Tangkai daun & Colletotrichum sp. \\
\hline 4. & Belimbing (Averrhoa carambola L.) & $\begin{array}{l}\text { Tangkai daun } \\
\text { Daun }\end{array}$ & $\begin{array}{l}\text { Colletotrichum sp. } \\
\text { Unidentified }\end{array}$ \\
\hline 5. & Cabe keriting (Capsicum sp.) & $\begin{array}{l}\text { Buah } \\
\text { Batang } \\
\end{array}$ & $\begin{array}{l}\text { Cladosporium sp. } \\
\text { Cladosporium sp. }\end{array}$ \\
\hline 6. & Caisin (Brassica chinensis L.) & $\begin{array}{l}\text { Tangkai daun } \\
\text { Daun }\end{array}$ & $\begin{array}{l}\text { Fusarium sp. } \\
\text { Unidentified }\end{array}$ \\
\hline 7. & Cantel (Sorghum bicolor L.) & Tangkai daun \& *daun & Cladosporium sp. \\
\hline 8. & $\begin{array}{l}\text { Cermai jepang (Phyllanthus distichus } \\
\text { L.) }\end{array}$ & Tangkai daun \& daun & Unidentified \\
\hline 9. & Jagung (Zea mays L.) & Batang & $\begin{array}{l}\text { Drechslera sp. } \\
\text { Fusarium sp. }\end{array}$ \\
\hline 10. & $\begin{array}{l}\text { Jambu air (Syzygium aqueum Burn.f) } \\
\text { Alston }\end{array}$ & $\begin{array}{l}\text { Ranting } \\
\text { Daun }\end{array}$ & $\begin{array}{l}\text { Unidentified } \\
\text { G. endophyllicola }\end{array}$ \\
\hline 11. & $\begin{array}{l}\text { Jambu bol (Syzygium malaccense } \\
\text { Merr. \& Perry) }\end{array}$ & $\begin{array}{l}\text { Ranting } \\
\text { Daun }\end{array}$ & $\begin{array}{l}\text { Colletotrichum.sp. } \\
\text { Colletotrichum sp } \\
\text { G. endophyllicola }\end{array}$ \\
\hline 12. & Jeruk asam (Citrus sp.) & $\begin{array}{l}\text { Tangkai daun } \\
\text { Daun }\end{array}$ & $\begin{array}{l}\text { Unidentified } \\
\text { Colletotrichum sp. } \\
\text { G. endophyllicola }\end{array}$ \\
\hline
\end{tabular}




\begin{tabular}{|c|c|c|c|}
\hline No & Tanaman inang & Bagian tanaman & Jamur \\
\hline 13. & Jeruk bali (Citrus grandis (L.) Osbeck) & $\begin{array}{l}\text { Tangkai daun } \\
\text { Daun } \\
\text { Buah } \\
\text { Bunga }\end{array}$ & $\begin{array}{l}\text { Cladosporium sp. } \\
\text { Colletotrichum sp. } \\
\text { Curvularia sp. } \\
\text { Coelomycetes } \\
\text { Cladosporium sp. } \\
\text { Colletotrichum sp. } \\
\text { Colletotrichum sp. }\end{array}$ \\
\hline 14. & Jeruk gede (Citrus reticulata Blanco) & $\begin{array}{l}\text { Tangkai daun } \\
\text { Daun }\end{array}$ & $\begin{array}{l}\text { Colletotrichum sp. } \\
\text { Colletotrichum sp. } \\
\text { G. endophyllicola }\end{array}$ \\
\hline 15. & Kacang kapri (Pisum sativum L.) & $\begin{array}{l}\text { *Tangkai daun } \\
\text { Daun }\end{array}$ & $\begin{array}{l}\text { Colletotrichum sp. } \\
\text { Colletotrichum sp. } \\
\text { Pestalotiopsis sp. } \\
\end{array}$ \\
\hline 16. & Kacang tanah (Arachis hypogaea L.) & Daun & Unidentified \\
\hline 17. & Kangkung (Ipomoea aquatica Forsk) & ${ }^{*}$ Daun & $\begin{array}{l}\text { Colletotrichum sp. } \\
\text { Fusarium sp. }\end{array}$ \\
\hline \multicolumn{4}{|l|}{18.} \\
\hline & $\begin{array}{l}\text { Kedongdongan (Lannea } \\
\text { coromandelica (Houtt.) Merr.) }\end{array}$ & $\begin{array}{l}\text { Tangkai daun } \\
\text { Daun } \\
\end{array}$ & $\begin{array}{l}\text { Colletotrichum sp. } \\
\text { Cladosporium sp. }\end{array}$ \\
\hline 19. & $\begin{array}{l}\text { Kembang sepatu } \\
\text { (Hibiscus sabdariffa L.) }\end{array}$ & $\begin{array}{l}\text { Tangkai daun } \\
\text { Daun }\end{array}$ & $\begin{array}{l}\text { Colletotrichum sp. } \\
\text { Paecilomyces lilacinus } \\
\text { (Thom) Samson } \\
\text { Colletotrichum sp. } \\
\text { G. endophyllicola } \\
\end{array}$ \\
\hline 20. & Kol (Brassica oleracea L.) & Tangkai daun & Unidentified \\
\hline 21. & Kopi (Coffea sp.) & $\begin{array}{l}\text { Tangkai daun } \\
\text { Daun } \\
\text { Bunga }\end{array}$ & $\begin{array}{l}\text { Unidentified } \\
\text { Colletotrichum sp. } \\
\text { G. endophyllicola } \\
\text { Nigrospora oryzae } \\
\text { (Berk. \& Broome) Petch } \\
\text { N. oryzae }\end{array}$ \\
\hline 22. & Lobak (Raphanus sativus L.) & Daun & Unidentified \\
\hline 23. & Melastoma sp. & $\begin{array}{l}\text { Tangkai daun } \\
\text { Daun } \\
\end{array}$ & $\begin{array}{l}\text { Unidentified } \\
\text { G. endophyllicola }\end{array}$ \\
\hline 24. & Nanas (Ananas comosus (L.) Merr.) & Daun & $\begin{array}{l}\text { Colletotrichum sp. } \\
\text { Pestalotiopsis sp. }\end{array}$ \\
\hline 25. & Padi (Oryza sativa L) & Batang & Unidentified \\
\hline
\end{tabular}




\begin{tabular}{|c|c|c|c|}
\hline No & Tanaman inang & Bagian tanaman & Jamur \\
\hline 26. & Pepaya (Carica papaya L.) & Daun & Cladosporium sp. \\
\hline 27. & Pokcai (Brassica sp & Tangkai daun & $\begin{array}{l}\text { Aspergillus sp. } \\
\text { Penicillium sp. }\end{array}$ \\
\hline 28. & $\begin{array}{l}\text { Sawi (Brassica juncea (L.) Czern. \& } \\
\text { Coss }\end{array}$ & Daun & Unidentified \\
\hline 29. & Selada merah (Lactuca sativa L.) & Tangkai daun & Cladosporium sp. \\
\hline 30. & Selada hijau (L. sativa L.) & $\begin{array}{l}\text { Tangkai daun } \\
\text { Daun }\end{array}$ & $\begin{array}{l}\text { Cladosporium } \mathrm{sp} \text {. } \\
\text { P. lilacinus }\end{array}$ \\
\hline 31. & Sereh (Ophiophogon sp.) & Batang \& daun & Unidentified \\
\hline 32. & Strawberi & $\begin{array}{l}\text { Tangkai daun } \\
\text { Daun }\end{array}$ & $\begin{array}{l}\text { Colletotrichum sp. } \\
\text { Cladosporium sp. } \\
\text { G. endophyllicola }\end{array}$ \\
\hline 33. & Terong (Solanum melongena L.) & $\begin{array}{l}\text { Tangkai daun } \\
\text { Daun }\end{array}$ & $\begin{array}{l}\text { Cladosporium sp. } \\
\text { Cladosporium sp. }\end{array}$ \\
\hline 34. & $\begin{array}{l}\text { Terong susu (Solanum mammosum } \\
\text { L.) }\end{array}$ & $\begin{array}{l}\text { Tangkai daun } \\
\text { Daun \& buah }\end{array}$ & $\begin{array}{l}\text { Fusarium sp. } \\
\text { Unidentified }\end{array}$ \\
\hline 35. & $\begin{array}{l}\text { Tomat (Lycopersicon lycopersicum (L.) } \\
\text { Kaersten }\end{array}$ & $\begin{array}{l}\text { Buah } \\
\text { Bunga } \\
\text { Daun }\end{array}$ & $\begin{array}{l}\text { Curvularia sp. } \\
\text { Unidentified } \\
\text { Cladosporium sp. }\end{array}$ \\
\hline 36. & Ubi jalar (Ipomoea batatas (L.) Lamk) & $\begin{array}{l}\text { *Batang } \\
\text { Daun }\end{array}$ & $\begin{array}{l}\text { Fusarium sp. } \\
\text { Colletotrichum sp. } \\
\text { Fusarium sp. }\end{array}$ \\
\hline 37. & $\begin{array}{l}\text { Wortel (Daucus carota L. ssp. sativus } \\
\text { Hayek) }\end{array}$ & $\begin{array}{l}\text { Tangkai daun } \\
\text { Umbi }\end{array}$ & $\begin{array}{l}\text { Unidentified } \\
\text { Fusarium sp. }\end{array}$ \\
\hline \multicolumn{4}{|c|}{ Tanaman hutan penunjang } \\
\hline 38. & Araucaria sp. & Daun & $\begin{array}{l}\text { Colletotrichum sp. } \\
\text { G. endophyllicola } \\
\text { Nigrospora sp. }\end{array}$ \\
\hline 39. & Bambu (Schyzostachyum sp.) & Tangkai daun \& daun & Unidentified \\
\hline 40. & HP-1 (Clotalaria incana) & Tangkai daun \& daun & Unidentified \\
\hline 41. & HP-3 (Clitoria ternatea L.) & $\begin{array}{l}\text { Tangkai daun } \\
\text { Polong } \\
\text { Daun }\end{array}$ & $\begin{array}{l}\text { Phoma sp } \\
\text { Dematiaceae } \\
\text { Phomopsis sp. } \\
\text { Phoma sp. }\end{array}$ \\
\hline
\end{tabular}




\begin{tabular}{|c|c|c|c|}
\hline No & Tanaman inang & Bagian tanaman & Jamur \\
\hline 42. & HP-4 (Eupatorium odoratum L.) & $\begin{array}{l}\text { Tangkai daun } \\
\text { Daun }\end{array}$ & $\begin{array}{l}\text { Cladosporium sp. } \\
\text { Colletotrichum sp } \\
\text { Fusarium sp. } \\
\text { G. endophyllicola }\end{array}$ \\
\hline 43. & HP-5 (Hyptis pectinata Poir) & $\begin{array}{l}\text { Tangkai daun } \\
\text { Bunga }\end{array}$ & $\begin{array}{l}\text { Cladosporium sp. } \\
\text { Fusarium sp. } \\
\text { Cladosporium sp. }\end{array}$ \\
\hline 44. & HP-6 (Toona suremi Merr.) & $\begin{array}{l}\text { Tangkai daun } \\
\text { Daun }\end{array}$ & $\begin{array}{l}\text { Cladosporium sp. } \\
\text { Fusarium sp. } \\
\text { Unidentified }\end{array}$ \\
\hline 45. & HP-7 (Swietenia mahagoni Jack) & $\begin{array}{l}\text { Tangkai daun } \\
\text { Daun } \\
\end{array}$ & $\begin{array}{l}\text { Phomopsis sp. } \\
\text { G. endophyllicola }\end{array}$ \\
\hline 46. & HP-8 (Hyptis capitata Jack) & $\begin{array}{l}\text { Tangkai daun } \\
\text { Daun } \\
\text { Bunga }\end{array}$ & $\begin{array}{l}\text { G. endophyllicola } \\
\text { Colletotrichum sp } \\
\text { G. endophyllicola } \\
\\
\text { Cladosporium sp. } \\
\text { Colletotrichum sp } \\
\text { Unidentified }\end{array}$ \\
\hline 47. & HP-9 (Selaginella plam) & $\begin{array}{l}\text { Tangkai daun } \\
\text { Daun }\end{array}$ & $\begin{array}{l}\text { F. oxysporum } \\
\text { Colletotrichum sp }\end{array}$ \\
\hline 48. & HP-13 (Solanum toruum) & Daun & $\begin{array}{l}\text { Colletotrichum } \mathrm{sp} \\
\text { F. oxysporum }\end{array}$ \\
\hline 49. & Pinus merkusii Jungh. \& De Vries & Tangkai daun & Unidentified \\
\hline
\end{tabular}

Dari 214 isolat jamur endofit yang diuji aktivitas agen biokontrolnya, 39 isolat $(18,22$ $\%)$ mampu menghambat pertumbuhan $\mathrm{R}$. solani dengan persen hambatan 10,18$58,99 \%$ (Tabel 3 ). Jamur-jamur yang mampu menghambat pertumbuhan $R$. solani adalah Cladosporium, Colletotrichum, Curvularia, Drechslera, Fusarium, Guignardia endophyllicola, Nigrospora, Paecilomyces lilacinus,
Pestalotiopsis sp., Phoma, dan Phomopsis. Hambatan pertumbuhan $R$. solani tertinggi masing-masing diperlihatkan oleh jamur belum terindentifikasi yang diisolasi dari Hyptis capitata (58,99 \%), Cladosporium sp. yang diisolasi dari jeruk bali $(55,42 \%)$, Pestalotiopsis sp. yang diisolasi dari nanas $(53,85 \%)$, dan Paecilomyces lilacinus (Thom) Samson yang diisolasi dari beringin $(51,81 \%)$. 
Tabel 3. Skrining aktivitas agen biokontrol terhadap Rhizoctonia solani dari jamur endofit yang diisolasi dari tanaman pertanian dan tanaman hutan penunjang yang tumbuh di Desa Parakanan Salak dan Cimalati, Sukabumi.

\begin{tabular}{|c|c|c|c|}
\hline No & Tanaman inang & Jamur & $\begin{array}{c}\text { Hambatan pertumbuhan } \\
\text { R. solani }(\%)\end{array}$ \\
\hline 1. & H. capitata & Cladosporium sp. & 12,16 \\
\hline 2. & H. pectinata & Cladosporium sp. & 11,49 \\
\hline 3 & Jeruk bali & Cladosporium sp. & 55,42 \\
\hline 4. & Cantel & Cladosporium sp. & 26,51 \\
\hline 5. & Tomat & Cladosporium sp. & 41,57 \\
\hline 7. & Jeruk bali & Colletotrichum sp. & 14,37 \\
\hline 8. & Nanas & Colletotrichum sp. & 16,17 \\
\hline 9. & Ubi jalar & Colletotrichum sp. & 15,54 \\
\hline 10. & Beringin & Curvularia sp. & 15,06 \\
\hline 11. & Jagung & Drechslera sp. & 39,24 \\
\hline 12. & Daun bawang & F. oxysporum & 10,18 \\
\hline 13. & Jeruk nipis & F. oxysporum & 34,73 \\
\hline 14. & S. plam & F. oxysporum & 31,0 \\
\hline 15. & S. toruum & F. oxysporum & 27,54 \\
\hline 16. & Jambu air & F. oxysporum & 25,26 \\
\hline 17. & Babadotan & Fusarium sp. & 23,35 \\
\hline 18. & Caisin & Fusarium sp. & 29,34 \\
\hline 19. & C. usaramoensis & Fusarium sp. & 26,95 \\
\hline 20. & E. odoratum & Fusarium sp. & 45,5 \\
\hline 21. & Jahe merah & Fusarium sp. & 24,85 \\
\hline 22. & Jambu biji & Fusarium sp. & 26,35 \\
\hline 23. & Jambu bol & Fusarium sp. & 12,84 \\
\hline 24. & Kacang panjang & Fusarium sp. & 25,15 \\
\hline 25. & Kedelai & Fusarium sp. & 27,54 \\
\hline 26. & Mahkota dewa & Fusarium sp. & 18,10 \\
\hline 27. & Talas & Fusarium sp. & 27,54 \\
\hline 28. & T. suremi & Fusarium sp. & 32,94 \\
\hline 29. & Wortel & Fusarium sp. & 19,76 \\
\hline 30. & Jambu biji & G. endophyllicola & 48,34 \\
\hline 31. & Kopi & N.oryzae & 11,45 \\
\hline 32. & Kembang sepatu & P. lilacinus & 51,81 \\
\hline 33. & Selada hijau & $P$. lilacinus & 22,16 \\
\hline 34. & Jambu mawar & Pestalotiopsis sp. & 40,10 \\
\hline 35. & Nanas & Pestalotiopsis sp. & 53,85 \\
\hline 36. & Teh & Pestalotiopsis sp. & 28,14 \\
\hline 37. & C. ternatea & Phoma sp. & 14,57 \\
\hline 38. & Mahkota dewa & Phomopsis sp. & 25,90 \\
\hline 39. & H. capitata & Unidentified & 58,99 \\
\hline
\end{tabular}




\subsection{Pembahasan}

Tidak terisolasinya jamur endofit pada tanaman kangkung dan genjer yang tumbuh di Desa Parakan Salak, mungkin disebabkan kedua tanaman tersebut dalam kondisi terendam air sehingga jamur tidak hidup atau kalah oleh bakteri meskipun media pertumbuhan untuk jamur endofit telah diberi antibakteri kloramfenikol.

Komposisi jamur pada dua tempat pengambilan sampel agak sedikit berbeda. Mucor dan Rhizoctonia ditemukan di Desa Parakan Salak tetapi tidak ditemukan di Desa Cimalati. Sebaliknya, Aspergillus, Penicillium, Cladosporium, P. lilacinus, dan Phoma ditemukan di Desa Cimalati tetapi tidak ditemukan di Desa Parakan Salak. Kemungkinannya disebabkan oleh komposisi tanaman dan kondisi lingkungan yang berbeda.

Kecuali pada tanaman jagung, spesies/ marga jamur endofit yang diisolasi dari aneka organ tanaman yang berbeda dari tanaman yang sama; dan tanaman yang sama dari tempat pengambilan sampel yang berbeda, menunjukkan perbedaan. Habitat yang berkaitan dengan tumbuhan merupakan lingkungan yang dinamis, menyebabkan banyak faktor dapat mempengaruhi komposisi jamur endofit. Okane et al. ${ }^{13)}$ melaporkan bahwa komposisi jamur endofit berkaitan erat dengan tempat dan tumbuhan inang. Rubini et al. ${ }^{14)}$ menginformasikan bahwa komunitas jamur endofit mungkin tergantung pada interaksi dengan mikroorganisme endofit atau patogen lainnya. Keberadaan jamur endofit pada tumbuhan tampaknya dipengaruhi oleh variasi musim ${ }^{15)}$, faktor lingkungan ${ }^{16)}$, dan tipe jaringan tumbuhan inang ${ }^{15)}$.

Filtrat dari 39 isolat jamur endofit memperlihatkan aktivitas antibiosis terhadap patogen tanaman $R$. solani yang digunakan untuk uji toksisitas. Berikut ini adalah beberapa contoh penelitian yang mendukung hasil penelitian tersebut. Alkaloid asfermufoid, aspernigrin $\mathrm{A}$, dan aspernigerin diisolasi dari
Cladosporium herbarum (pers.) Link ex S.O Gray yang berinteraksi dengan Cynodon dactylon K. Nov. dapat menghambat C. albicans dan sel tumor ${ }^{17)}$. Colletotrichum mempunyai antifungi terhadap Rhizoctonia cerealis van Der Hoeven, Phytophthora capsici Lionian, Gaeumannomyces graminis var tritici dan Helminthosporium sativum Pammel. ${ }^{18)}$. Curvularia lunata yang diisolasi dari bunga karang Niphantes olemda menghasilkan lunatin yang aktif melawan Bacillus subtilis, Staphylococcus aureus, dan Escherichia coli ${ }^{19)}$. Fusarium yang diisolasi dari Selaginella pallescens (Presl.) Spring menghasilkan pentaketida yang bersifat antifungi ${ }^{20)}$. Fusarium nivale (Fr.) Ces. yang diisolasi dari anggrek merpati dapat menghambat pertumbuhan Candida albicans dan C. tropicalis ${ }^{10)}$, serta menghambat Absidia corymbifera ${ }^{21)}$. Jamur yang sama menghasilkan mikotoksin nivalenol yang dapat menghambat sintesis protein ${ }^{22)}$; menghasilkan mikotoksin fusarenon-x 23), dan deoxynivalenol (DON, vomitoxin) 24). Guignardia (anamorf: Phyllosticta) yang berasosiasi dengan Abies balsamea menghasilkan heptelidic acid dan hydroheptelidic acid yang toksik pada larva Choristoneura fumiferana ${ }^{18)}$. Nigrospora oryzae dapat menghambat perkecambahan spora dan pertumbuhan miselium Fusarium avenaceum, F. culmorum, F. gramminearum, $F$. gramminearum, F. oxysporum, $F$. equiseti, F. lateritium and Botrytis cinerea 25). Paecilomyces lilacinus menghasilkan metabolit sekunder yang dapat melawan bermacam nematoda yang menyerang akar tanaman ${ }^{26)}$. Pestalotiopsis yang diisolasi dari Terminalia arjuna memperlihatkan aktivitas antifungi terhadap Alternaria carthani, F. oxysporum, F. verticilloides, Macrophomina phaseolina, Phoma sorghina, Sclerotium sclerotiorum ${ }^{27)}$. Phomopsis sp. 1 yang diisolasi dari tanaman obat cina dapat menghambat pertumbuhan Scopulariopsis dan Verticillium, sedangkan Phomopsis sp. 2 dapat menghambat pertumbuhan Colletotrichum gloeosporioides dan Fusarium 
sp. ${ }^{28)}$. Jamur Phoma menghasilkan quinone yang bersifat antifungi terhadap Alternaria sp. dan 2-Hydroxy-6-methylbenzoic acid yang bersifat antibakteri ${ }^{18)}$. Phoma $\mathrm{sp}$. yang diisolasi dari tanaman obat cina dapat menghambat pertumbuhan $C$. gloeosporioides, Scopulariopsis sp., T. viride, dan Verticillium sp. ${ }^{28)}$.

Ketidakmampuan isolat jamur endofit lainnya menghambat pertumbuhan $R$. solani, kemungkinannya tidak mengandung metabolit sekunder yang bersifat antifungi atau konsentrasi untuk pengujian terlalu rendah (200 $\mu \mathrm{l} / 5 \mathrm{ml}$ PDA) sehingga tidak dapat menghambat pertumbuhan $R$. solani. Kemungkinan lainnya, jamur endofit tersebut mengandung metabolit sekunder yang berfungsi lainnya.

\section{KESIMPULAN}

Sebanyak 214 isolat jamur endofit (101 isolat dari Desa Parakan Salak dan 113 isolat dari Desa Cimalati) berhasil diisolasi dari tanaman yang tumbuh di lahan pertanian dan lahan hutan penunjang G. Salak.

Jamur Mucor dan Rhizoctonia hanya terisolasi dari tanaman yang tumbuh di Desa Parakan Salak, sedangkan jamur Aspergillus, Cladosporium, Penicillium, $P$. lilacinus, dan Phoma hanya terisolasi dari tanaman yang tumbuh di Desa Cimalati.

Dari 214 isolat jamur endofit yang diuji, hanya ada 39 isolat $(18,22 \%)$ yang dapat menghambat pertumbuhan $R$. solani dengan persen hambatannya 10,18-58,99\%. Hambatan pertumbuhan $R$. solani tertinggi masing-masing diperlihatkan oleh jamur yang belum terindentifikasi yang diisolasi dari $H$. capitata $(58,99 \%)$, Cladosporium sp. yang diisolasi dari jeruk bali $(55,42 \%)$, Pestalotiopsis sp. yang diisolasi dari nanas $(53,85 \%)$, dan $P$. lilacinus yang diisolasi dari beringin $(51,81 \%)$.

\section{UCAPAN TERIMA KASIH}

Penulis mengucapkan terima kasih kepada DIKTI, Departemen Pendidikan Nasional yang telah membiayai penelitian ini. Terima kasih penulis sampaikan pula kepada Rachmat (teknisi Bidang Mikrobiologi, Puslit Biologi - LIPI) yang telah membantu penelitian ini; dan Bapak Lurah Parakan Salak serta Cimalati, Sukabumi beserta stafnya yang telah mengizinkan penulis mengambil sampel tanaman sebagai bahan penelitian.

\section{DAFTAR PUSTAKA}

1. Ogoshi A \& T Ui. 1983. Diversity of clones within an anastomosis group of Rhizoctonia solani Kuhn in a field. Annual Review of the Japan Phytophatological Society 49, 239-245.

2. Ogoshi A. 1987. Ecology and pathogenecity of anastomosis and intraspecific groups of Rhizoctonia solani Kuhn. Annual Review of Phytophatology 25, 125-143.

3. Campbell R. 1989. Biological control of microbiol plant pathogens. Cambride University Press, Cambridge.

4. Djatnika I, C Hermanto, \& Eliza. 2003. Pengendalian hayati layu fusarium pada tanaman pisang dengan Pseudomonas flourescens dan Gliocladium. J. Hortikultura 13, 203-211.

5. Bacon CW, IE yates, DM Hinton, \& F Meredith.

2001. The potential impact of climate variability and change on air pollutionrelated health effects in the United States. Environmental Health Perspectives 109(suppl.2), 325-332.

6. Nakagiri A, I Okane, T Ito, K Kramadibrata,

Suciatmih, \& A Retnowati. 2005. A Guidebook to identification of fungi inhabiting mangrove and surrounding 
area in Indonesia. A report of GTI pilot study on Fungal taxonomy.

7. Gandjar, I., I.R. Koentjoro, W. Mangunwardoyo, \& L. Soebagya. 1992. Pedoman praktikum mikrobiologi dasar, Jurusan Biologi, FMIPA, UI, Jakarta.

8. Domsch $\mathrm{KH}$, Gams W, \& Anderson T. 1980.

Compedium of soil fungi $\mathrm{Vol}$ I. Academic Press, London.

9. Ellis, M.B. 1993. Dematiaceous Hyphomycetes.

IMI, London.

10. Suciatmih. 2008. Isolasi, identifikasi, skrining, dan optimasi kapang endofit penghasil antimikroorganisme dari Dendrobium crumenatum Sw. (anggrek merpati), Tesis Pascasarjana. FMIPA UI, Depok: Tidak diterbitkan.

11. Prihatiningtias $\mathrm{W}, \mathrm{SM}$ Widyastuti, \& S Wahyuono. 2005. Senyawa antibakteri dari Thievalia polygonoperda, fungi endofit tumbuhan akar kuning (Fibraurea chloroleuca Miers). Pharmacon 6(1), 19-22.

12. Skidmore AM. \& CH Dickinson. 1976. Colony interactions and hyphal interference between Septoria nodurum and phylloplane fungi. Trans. Br. Mycol. Soc. 66, 57-64.

13. Okane I., A Nakagiri, \& T Ito. 1998. Endophytic fungi in leaves of ericaceous plants. Canadian Journal of Botany 76(4), 657-663.

14. Rubini MR, RT Silva-Ribeiro, AWV Pomella, CS

Maki, WLAraujo, DR. dos Santos, \& JL Azevedo. 2005. Diversity of endophytic fungal community of cacao (Theobroma cacao L.) and biological control of
Crinipellis perniciosa, causal agent of witches'broom disease. International journal of Biological Sciences 1, 24-33.

15. Mahesh N, MV Tejesvi, MS Nalini, HS Prakash,

KR Kini, Ven Subbiah, \& HS Shetty. 2005. Endophytic mycoflora of inner bark of Azadirachta indica A. Juss. Current Science 88(2), 218-219.

16. Clay K. 1986. Grass endophytes. In: N.J. Fokkema \& J.Van den Heuvel (ed.).Mycrobiology of the phyllosphere. Cambridge University Press, Cambridge: 166-204.

17. Hua Wei Zhang, Yong Chun Song, \& Ren Xiang Tan. 2006. Biology and chemistry of endophytes.

Natural Product Reports 23, 753-771.

18. Ren Xiang Tan \& Wen Xin Zou. 2001. Endophytes: a rich source of functional metabolites. Natural Product Reports 18, 448-459.

19. Jadulco R, G Brauers, RA Edrada, R Ebel, V Wray, Sudarsono, \& P Proksch. 2002. New metabolites from spongederived fungi Curvularia lunata and Cladosporium herbarum. J. Nat. Prod. 65 (5), 730-733.

20. Strobel G \& B Daisy. 2003. Bioprospecting for microbial endophytes and their natural products.

Microbiology and Molecular Biology Reviews 67(4), 491-502.

21. Suciatmih. 2010. Pengaruh konsentrasi antimikroorganisme, media fermentasi, dan waktu inkubasi terhadap Absidia corymbifera (Cohn.) Sacc. \& Trotter dari jamur endofit

Fusarium nivale (Fr.) Ces. Media Litbang Kesehatan 20(10), 17-25. 
22. Tatsumo T. 1969. Toxicologic research on subtances from Fusarium nivale. Cancer Research 28, 2393-2396.

23. Ueno $\mathrm{Y}, \mathrm{N}$ Sato, K Ishi, K Sakai, H Tsunoda, \& M Enomoto. 1973. Biological and chemical detection of trichothecene mycotoxins of Fusarium species. Applied Mycrobiology 25(4), 699-704.

24. Logrieco A, RF Vesonder, SW Peterson, \& Bottalico. 1991. Reexamination of the taxonomic disposition of and deoxynivalenol production by Fusarium nivale NRRL 3289. Mycologia 83(3), 367-370.

25. Szewczuk V, W Kita, B Jarosz, W Truszkowska, \& A Siewiński. 1991. Growth inhibition of some phytopathogenic fungi by organic extracts from Nigrospora oryzae (Berkeley and Broome) Petch. Journal of Basic Microbiology 31, 69-73.
26. Duan, W. E. Yong, M. Xiang, \& X. Liu. 2008.

Effect of storage conditions on the survival of two potential biocontrol agents of nematodes, the fungi Paecilomyces lilacinus and Pochonia chlamydosporia. Biocontrol Science and Technology 18(6), 613-620.

27. Tejesvi MV, KR Kini, HS Prakash, V Subbiah, \& HS Shetty. 2007. Genetic diversity and antifungal activity of species of Pestalotiopsis isolates as endophytes from medicinal plants. Fungal Diversity 24, 37-54.

28. Haiyan Li, Chen Qing, Yanli Zhang, \& Zhiwei Zhao. 2005. Screening for endophytic fungi with antitumor and antifungal activities from chinese medicinal plants. World Journal of Microbiology and Biotechnology 21, 1515-1519 